Rockefeller University

Digital Commons @ RU

$11-1915$

An Attempt at a Physico-Chemical Explanation of Certain Groups of Fluctuating Variation

Jacques Loeb

Mary Mitchell Chamberlain 


\title{
AN ATTEMPT AT A PHYSICO-CHEMICAL EXPLANA- TION OF CERTAIN GROUPS OF FLUCTUATING VARIATION
}

\author{
JACQUES LOEB AND MARY MITCHELL CHAMBERLAIN
}

I

There is a general tendency to visualize the factors which determine the hereditary characters as specific chemical compounds. If we wish to carry this view (with which we sympathize) beyond the limit of a vague statement, we must either try to establish the nature of these compounds by the methods of the organic chemist, or we must use the methods of general or physical chemistry and try to find numerical relations by which we can identify the quantities of the reacting masses or the ratio in which they combine. Attempts in this direction have been made by the suggestion of Loeb ${ }^{1}$ that phenomena of grow th belong in the group of auto-catalytic processes, and by T.B. Robertson' ${ }^{2}$ and Ostwald's investigations supporting and enlarging this idea; by A. R. Moore's ${ }^{3}$ attempt to show that in hybrids the velocity of development of the dominant character is slower than in the pure dominant breed; and by Loeb and Ewald's ${ }^{4}$ proof that all the embryos of Fundulus have practically the same rate of heart beat at the same temperature. Since our new experiments are a sequence of this last mentioned paper, we may briefly discuss its contents.

${ }^{1} \mathrm{~J}$. Loeb. Ueber den chemischen Character des Befruchtungsvorgangs Roux's Vorträge und Ausätze, Leipzig, 1908. Biochem. Ztschr., 2, 34, 1906.

2 T. B. Robertson. Roux's Archiv, 25, 581, 1908; 26, 108, 1908;.37, 497, 1913. Am. Jour. Physiol., 37, 1, 1915; Robertson and Wasteneys, Roux's Archiv, 37, 485, 1913; Wo. Ostwald. Ueber die zeitiichen Eigenschaften der Entwicklungsvorgänge, Leipzig, 1908.

3 A. R. Moore. Roux's Arehiv, 34, 168, 1912.

${ }^{4}$ J. Loeb and W. F. Ewald. Biochem. Ztschr., 58, 177, 1913. 
C. G. Rogers ${ }^{5}$ has shown that the heart beat of the embryo of Fundulus has a temperature coefficient of the order of the magnitude of a chemical reaction, i.e., that it practically doubles for an increase of temperature of $10^{\circ} \mathrm{C}$. Loeb and Ewald found that the rate of heart beat is practically the same in each individual embryo (of a certain age) for a given temperature, varying only in very narrow limits; so that the rate of the heart beat of any of these embryos could be utilized as a thermometer. The authors explained this fact on the basis of general chemistry as follows: given a sufficient quantity of substrate the velocity of the reaction is in proportion to the mass of enzyme. If we suppose that the rate of the heart beat is determined by the velocity of an enzyme reaction-which supposition agrees with the temperature coefficient-we must conclude that all hearts of Fundulus embryos must have the same mass of enzyme, since they all beat at the same rate when the temperature is the same. If we consider the rate of heart beat of the Fundulus embryo a hereditary character- which is legitimate- we are forced to the conclusion that each embryo of Fundulus inherits practically the same mass of those enzymes which are responsible for the heart beat. The hereditary factor in this case must consist of material which determines the formation of a given mass of these enzymes, since the factors in the chromosomes are too small to carry the whole mass of the enzymes existing in the embryo or adult.

II

While the rate of heart beat is approximately the same in each egg (at the right age) and for the same temperature, we notice slight variations, the usual fluctuating variation. It occurred to us that this fluctuating variation might offer a chance for further testing the enzyme conception of the factors of certain hereditary characters. We selected, instead of the rate of heart beat, the velocity of cell division. Loeb ${ }^{6}$ had shown in a former paper that the time from insemination to the first cell division

¿ C. G. Rogers. Am. Jour. Physiol., 28, 81, 1911.

' J. Loeb. Pflüger's Archiv, 124, 411, 1908. 
in the egg of the sea urchin Strongylocentrotus purpuratus can be so sharply measured and is so nearly constant that it can be used for the establishment of a temperature coefficient and this was later confirmed by Loeb and Wasteneys ${ }^{7}$ for the egg of Arbacia. Since the influence of temperature is again of the high order characteristic of chemical reactions, we may make the assumption that each egg carries a definite mass of one or more enzymes or catalysers which determine the rate of cell division. If we fertilize a mass of eggs of the same female of Arbacia and keep them at the same temperature, we find that they do not all begin to segment at the same time, and that there is an interval between the cell division of the first and last egg of the group. If we assume that the velocity of the cell division is determined by the mass of enzymes and the temperature, the fact that at $t^{\circ}$ some eggs divide after 100 , others after 101, 102, until, e.g., 113 minutes, we must conclude that this difference in time is the expression of a corresponding difference in the mass of enzymes in different eggs, those dividing in 100 minutes having a greater mass of enzymes than those dividing in 102, 103, etc., and 113 minutes; and that the mass of enzymes varies in inverse proportion to the time required for cell division at a given temperature. On this basis we should have to assume that the latitude of variation in the rate of cell division of a group of eggs is the expression of a corresponding variation in the mass of enzyme in the individual eggs. This idea can be put to a test with the aid of the temperature coefficient. . If we call $m$ the minimum mass of the enzyme responsible for the first cell division in the slowest eggs, then we shall find a certain greater percentage of eggs with the enzyme mass $m+a$, a still larger percentage with the mass $m+a_{2}$, and a small number with the mass $m+a_{n}$ where $m+a_{n}$. is the greatest mass of enzyme occurring in an egg. If the eggs with the mass $m+a_{n}$ divide at the temperature $\mathrm{t}^{\circ}$ after 100 minutes, they will divide in about $Q_{10} \times 100$ minutes at the temperature $(t-10)^{\circ}$, where $Q_{10}$ is the temperature coefficient for $10^{\circ} \mathrm{C}$. at this point; the eggs with the smallest mass of enzyme

${ }^{7}$ J. Loeb and H. Wasteneys. Biochem. Ztschr., 36, 345, 1911. 
$m$, which at $t^{\circ}$ divide after $113^{\prime}$ will divide at $(t-10)^{\circ}$ after $\mathrm{Q}_{10} \times 113$ minutes, since the temperature coefficient must be the same for both types of eggs. If we call the difference in the time of segmentation between the slowest and fastest egg the latitude of variation, this latitude of variation should vary in direct proportion to the temperature coefficient for cell division if our theory is correct.

\section{III}

We will first give the temperature coefficient of cell division for the egg of Arbacia for different temperatures; i.e., the results of measurement of the time required from the moment of insemination to the moment when the first egg in the field was seen to divide. The eggs had been kept in a water bath with constant temperature, and a little before the cell division was expected to occur (which time we knew from the former observations of Loeb and Wasteneys) the eggs were put into a watch glass of the temperature of the eggs and the exact time ascertained when the first egg of the lot underwent cell division. Table 1 gives these times according to Loeb and Wasteneys, and according to our own observations. The reader will notice how closely both values agree. ${ }^{8}$ Our values are the average of a number of determinations, which show only a negligible variation.

Beyond $31^{\circ}$ no segmentation occurs. We tried no experiments on the latitude of variation beyond $25^{\circ}$ or below $9^{\circ}$, since outside of these limits the segmentation is no longer entirely normal.

From the results of table 1 we compute the temperature coefficients for the time from insemination to the first appearance of cell division (table 2).

In order to determine the latitude of variation of the time of segmentation-i.e., the interval between the time at which the first egg of a set begins to segment and the time when the last egg segments for a certain temperature, we proceeded as

${ }^{8}$ The eggs were always used in the first hours after they had been removed from the animal. The time required for the first cell division was remarkably constant in different experiments. It is worth mentioning that such constancy is only possible when the temperature is kept constant. 
TABLE 1

Time in minutes from insemination to the cell division of the first egg in Arbacia

\begin{tabular}{|c|c|c|}
\hline TEMPERATURE & LOEB AND WASTENEYS & $\begin{array}{c}\text { LOEB AND } \\
\text { CHAMBEIRLAIN }\end{array}$ \\
\hline degrees: & & \\
\hline 7.0 & 498.0 & \\
\hline 8.0 & 410.0 & 411.0 \\
\hline 9.0 & 308.0 & 297.5 \\
\hline 10.0 & 217.0 & 208.5 \\
\hline 11.0 & 175.0 & 175.0 \\
\hline 12.0 & 147.0 & 148.0 \\
\hline 13.0 & & 129.0 \\
\hline 14.0 & & 116.0 \\
\hline 15.0 & 100.0 & 100.0 \\
\hline 16.0 & 85.5 & \\
\hline 17.5 & 70.5 & \\
\hline 18.0 & 68.0 & 68.0 \\
\hline 19.0 & & 65.0 \\
\hline 20.0 & 56.0 & 56.0 \\
\hline 21.0 & & 53.3 \\
\hline 22.0 & 47.0 & 46.0 \\
\hline 23.0 & & 45.5 \\
\hline 24.0 & & 42.0 \\
\hline 25.0 & 40.0 & 39.5 \\
\hline 26.0 & 33.5 & \\
\hline 27.5 & 34.0 & \\
\hline 30.0 & 33.0 & \\
\hline 31.0 & 37.0 & \\
\hline
\end{tabular}

follows: The eggs were inseminated in sea water, and kept in a water bath at the desired temperature. The eggs remained in this water bath until about the time when the first segmentation was expected to occur. In the meantime, a second water bath was prepared on the stage of the microscope whose temperature was slightly below that of the desired temperature. This water bath contained the watch glass in which the segmentation of the eggs was to be observed. The watch glass had therefore the temperature at which the eggs were observed. The temperature of this water bath was also kept constant. When the temperature at which the latitude of variation was observed was very low and that of the air of the room was high a slight error crept in, in as much as the temperature of the 
TABLE 2

\begin{tabular}{c|r}
\hline $\begin{array}{c}\text { TEMPRATURE } \\
\text { COEFTICINT FOR }\end{array}$ & \\
\hline $8 / 18$ & $\frac{410}{68}=6.0$ \\
$9 / 19$ & $\frac{297}{65}=4.5$ \\
$10 / 20$ & $\frac{208.5}{56}=3.7$ \\
$11 / 21$ & $\frac{175}{53.5}=3.3$ \\
$12 / 22$ & $\frac{146}{46}=3.2$ \\
$13 / 23$ & $\frac{129}{45.5}=2.8$ \\
$14 / 24$ & $\frac{116}{42}=2.8$ \\
$15 / 25$ & $\frac{100}{40}=2.5$ \\
\hline
\end{tabular}

water in the watch glass rose slightly during observation. This error made itself felt in that in the case of low temperatures the actual temperature was occasionally a trifle higher than intended. We shall come back to this point later on.

When the eggs had been put into the watch glass, a field with no less than 80 and often as many as 150 eggs was selected, and every minute the number of eggs which underwent cell division was counted until the last egg had divided. Very often a small percentage of the eggs had remained unfertilized and these of course did not divide. ${ }^{9}$ In table 3 we give a few examples of the actual measurements of the latitude of variation in the time required from the segmentation of the first to that of the last egg in a field.

As far as the irregularities in the first two minutes are concerned, they must probably be attributed to the fact that the entrance of the spermatozoa into the eggs occurred somewhat irregularly, the moment of insemination differing in various eggs within one or two minutes. Table 4 gives the latitude of varia-

${ }^{9}$ When this number was great the material could not be used since in such cases the spermatozoa no longer entered the eggs simultaneously. 
TABLE 3

Latitude of variation in segmentation time

\begin{tabular}{|c|c|c|c|c|c|c|}
\hline \multirow{4}{*}{$\begin{array}{c}\text { YUMBER OF } \\
\text { EGGS SEG- } \\
\text { MENTED } \\
\text { AFTER }\end{array}$} & \multicolumn{6}{|c|}{ TEMPERATURE } \\
\hline & $25^{\circ}$ & $15^{\circ}$ & $22^{\circ}$ & $22^{\circ}$ & $12^{\circ}$ & $12^{\circ}$ \\
\hline & \multicolumn{6}{|c|}{ Number of eggs in field } \\
\hline & 117 & 127 & 116 & 126 & 116 & 100 \\
\hline $\begin{array}{c}\text { minutes } \\
1 \\
2 \\
3 \\
4 \\
5 \\
6 \\
7 \\
8 \\
9 \\
10 \\
11 \\
12 \\
13 \\
14 \\
15 \\
16 \\
17 \\
18 \\
19 \\
20 \\
21 \\
22 \\
23 \\
24 \\
25\end{array}$ & $\begin{array}{r}3 \\
12 \\
34 \\
68 \\
107 \\
10 \text { eggs not } \\
\text { fertilized }\end{array}$ & $\begin{array}{r}1 \\
6 \\
15 \\
34 \\
44 \\
62 \\
79 \\
90 \\
95 \\
100 \\
109 \\
18 \text { eggs not } \\
\text { fertilized }\end{array}$ & $\begin{array}{r}1 \\
8 \\
21 \\
33 \\
85 \\
103 \\
110 \\
116\end{array}$ & $\begin{array}{c}2 \\
24 \\
49 \\
85 \\
95 \\
111 \\
117 \\
119 \\
7 \text { eggs not } \\
\text { fertilized }\end{array}$ & \begin{tabular}{|c|}
4 \\
15 \\
26 \\
40 \\
51 \\
60 \\
67 \\
77 \\
80 \\
80 \\
88 \\
88 \\
88 \\
90 \\
92 \\
95 \\
100 \\
101 \\
105 \\
105 \\
106 \\
108 \\
8 eggs not \\
fertilized
\end{tabular} & $\begin{array}{r}3 \\
5 \\
8 \\
10 \\
12 \\
16 \\
19 \\
20 \\
24 \\
28 \\
32 \\
36 \\
38 \\
49 \\
60 \\
75 \\
84 \\
85 \\
\\
85 \\
95 \\
96 \\
2 \text { eggs not } \\
\text { fertilized }\end{array}$ \\
\hline
\end{tabular}

tion, i.e., the difference in time between the segmentation of the last and that of the first egg in a field for different temperatures for all observations made. The averages appear in the last line.

This series illustrates the source of error to which we have already alluded, namely, that at low temperatures the times 
TABLE 4

Differences in minutes between segmentation of first and last egg in a field at

\begin{tabular}{|c|c|c|c|c|c|c|c|c|c|c|c|c|c|c|}
\hline $9^{\circ}$ & $10^{\circ}$ & $11^{\circ}$ & $12^{\circ}$ & $13^{\circ}$ & $14^{\circ}$ & $15^{\circ}$ & $18^{\circ}$ & $19^{\circ}$ & $20^{\circ}$ & $21^{\circ}$ & $22^{\circ}$ & $23^{\circ}$ & $24^{\circ}$ & $27^{\circ}$ \\
\hline $\begin{array}{l}50 \\
49 \\
47 \\
64 \\
60 \\
46\end{array}$ & $\begin{array}{l}39 \\
40\end{array}$ & $\begin{array}{l}25 \\
26 \\
27\end{array}$ & $\begin{array}{l}22 \\
20 \\
22\end{array}$ & $\begin{array}{c}20 \\
18 \\
(13) \\
19 \\
20 \\
18 \\
20\end{array}$ & $\begin{array}{l}17 \\
19 \\
16 \\
18\end{array}$ & $\begin{array}{l}13 \\
12 \\
12 \\
12 \\
14 \\
14 \\
12 \\
14 \\
14\end{array}$ & $\begin{array}{r}12 \\
11 \\
13 \\
\end{array}$ & $\begin{array}{l}14 \\
13 \\
11 \\
12 \\
12 \\
14\end{array}$ & $\begin{array}{r}10 \\
10 \\
9\end{array}$ & 8 & $\begin{array}{l}8 \\
7 \\
8 \\
9 \\
7 \\
8 \\
8 \\
8 \\
7 \\
8 \\
8\end{array}$ & $\begin{array}{l}9 \\
7 \\
9 \\
8 \\
8 \\
7\end{array}$ & $\begin{array}{l}7 \\
9 \\
7 \\
77 \frac{1}{2} \\
9 \\
8\end{array}$ & $\begin{array}{l}5 \\
5 \\
5\end{array}$ \\
\hline Mean 52.6 & 39.5 & 26 & 22.5 & 19.2 & $17.5 \mid$ & 13 & 12 & 12.5 & 9.6 & 8 & 7.8 & 8 & 8 & $5 \mathrm{Min}$ \\
\hline
\end{tabular}

were liable to be too short when the outside temperature was very high. Thus the value 13 minutes for the temperature of $13^{\circ}$ is unquestionably too low, and probably the values 46 and 47 for $9^{\circ} \mathrm{C}$. are also too low. At the higher temperatures the values differ much less, since the temperatures approximate much more the room temperature.

We are now in a position to compare the expected with the observed result. The expected result is the series of temperature coefficients for the time from insemination to the time when the first egg of the set begins to divide; the observed result is the series of temperature coefficients for the latitude of variation, i.e., the time which elapses between the segmentation of the first and last egg in a set. These two sets of coefficients should be identical and table 5 shows the degree of agreement.

A comparison shows that the temperature coefficients for the latitude of variation are practically identical with the temperature coefficients for cell division, and that where a noticeable difference exists it is always in the same direction, namely, the coefficients for the latitude of variation are a trifle too small. We can account for this on the basis of the deficiency in the method we have already discussed, namely that when the temperature of observation was low and that of the room high, the 
TABLE 5

Temperature coefficients for latitude of variation

\begin{tabular}{c|c|c}
\hline TEMPERATCRES & EXPECTED & FOUND \\
\cline { 2 - 3 } $9 / 19$ & 4.7 & $\frac{52.6}{12.6}=4.2$ \\
$10 / 20$ & 3.8 & $\frac{39.5}{10}=3.9$ \\
$11 / 21$ & 3.3 & $\frac{26}{8}=3.2$ \\
$12 / 22$ & 3.1 & $\frac{22.5}{7.8}=2.8$ \\
$13 / 23$ & 2.8 & $\frac{19.2}{8}=2.4$ \\
$14 / 24$ & 2.8 & $\frac{17.5}{8}=2.3$ \\
$15 / 25$ & 2.5 & $\frac{13}{5}=2.6$ \\
\hline
\end{tabular}

temperature in the watch glass may have risen slightly during the observations. Since in the determination of the temperature coefficient the value for the low temperature forms the numerator, it is obvious that the observed temperature coefficients are liable to be a little smaller than they would be without this error. We expect to test this idea next season.

\section{THEORETICAL REMARKS}

It was found in a previous investigation that the time which elapses from the moment of insemination to the moment of the beginning of cell division in the egg of Arbacia, is a constant for a given temperature. On the basis of the enzyme theory this was to be explained on the assumption that the mass of ferments contained in the egg of the sea urchin responsible for this process is approximately constant in each individual egg. This would mean that the hereditary factor determining the rate of cell division consists in determiners for definite quantities of ferments. This idea was put to a test by applying it to the fluctuating variability of this process. While for a given temperature the eggs of Arbacia will always begin to segment at the same time, not all the eggs segment simultaneously. Assuming 
that those eggs which segment first have a greater mass of ferment than the others, fluctuating variability would in this case be due to differences in the mass of ferment in the different eggs of the same female. If this idea were correct, eggs with the maximum and with the minimum amount of ferment should differ in the rate of segmentation by an amount of time which would vary in direct proportion to the temperature coefficient for the process of segmentation. This theory was tested and it was found that the observed values agree very closely with the expected values; the slight variations found being in the direction of the possible source of error of the method of the experiments. These experiments support therefore the idea that the hereditary factor responsible for the rate of segmentation is a determiner for a given mass of certain ferments, and that fluctuating variability depends in this case upon slight but definite variations in the mass of those ferments in different eggs.

\section{SUMMARY OF RESULTS}

1. It is shown that the temperature coefficient for the latitude of variation of the segmentation of the egg of Arbacia (i.e., the time between the segmentation of the first and last egg of a group fertilized at the same time) is practically identical with the temperature coefficient for segmentation.

2. It is shown that the fact is intelligible on the assumption that the fluctuating variation in this case is due to a variation in the mass of enzyme contained in the different eggs and supposed to be responsible for the rate of segmentation. 